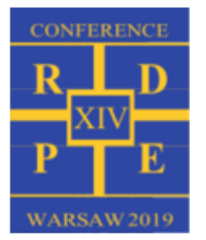

\title{
Quantity and Quality of Dual Fuel IC Marine Engine Exhaust Sensible Waste Heat Considering Different Sulphur Content in Fuels
}

\author{
Mateusz Przybyła ${ }^{1,}$, Andrzej A damkiewicz ${ }^{2}$ \\ 1 mateusz.przybyla@wp.pl,Poland \\ $2 \mathrm{M}$ aritime U niversity in Szczecin, a.adamkiewicz@am.szczecin.pl, Poland
}

\begin{abstract}
Maritime transport is facing a significant set of technical challenges due to planned by the International M aritime Organization implementation of ecological criterions on 01 January 2020 and 2021 regarding the emission of sulphur oxides, carbon dioxide and nitrogen oxides. The advantageous properties of natural gas (NG) as fuel in conjunction with dual fuel (DF) internal combustion (IC) engines potentially enables the fulfilment of all planned criterions. However, if the methane emission of DF IC is taken into consideration in $\mathrm{CO} 2$ emission balance it completely devaluates the advantages arising from high hydrogen to carbon ratio of NG. On the other hand, the planned global sulphur cap in combination with its low content in NG potentially enables to recover higher rates of waste heat and exergy of combustion products without the risk of low temperature corrosion (compared to liquid fuel). In this study the influence of sulphur content in NG and pilot fuel on the sulphuric acid condensation temperature was investigated in order to determine the rate of waste heat (quantity) and exergy (quality) of four stroke DF IC engine combustion products. In ideal process scenario (exergy based) the methane slip effect compensation was achieved only for a 0,5 engine load.
\end{abstract}

\section{Introduction}

The decision made by the International Maritime Organization (IM O) on the simultaneous implementation of regulations on 01 January 2020 regarding the global sulphur content in marine fuel and the energy efficiency of ships poses a new, complex set of problems for maritime transport. In the case of vessels operated within the Baltic and North Sea areas this set of problems is extended by the implications resulting from the decision to classify them on $01 \mathrm{~J}$ anuary 2021 as Emission Control A rea (ECA) [1].

Using low-sulphur fuel (fuel with sulphur mass fraction not exceeding $0.5 \%$ ) in order to meet the first of these criteria leaves the problem of excessive emission of nitrogen oxides unsolved. M eeting the Tier III criterion implies the need to process combustion products in the Selective Catalytic Reduction (SCR) system. On the other hand, the SCR system significantly limits the possibility of exhaust waste heat conversion due to the required minimum temperature determining the efficiency of the process [2]. In addition, the amount of available waste heat flux of liquid fuel exhaust gases and the efficiency of its conversion is limited mainly by the condensation temperature of the sulphuric acid [3].

Liquified $N$ atural Gas ( $L N G)$ is an al ternative marine fuel that reduces the problems described above. The advantageous properties of natural gas (NG) enabling the fulfilment of the IMO ecological criteria are the main reason for significant changes in the configuration of LNG tanker power systems (LNGC - Liquified Natural
Gas Carriers). The quantitative shares of ship power systems with steam turbines (ST - Steam Turbine) recognized on the basis of [4] had amounted to $100 \%$ in the LNGC population until 2004. Due to the higher effective efficiency of dual fuel (DF) piston engines and favorable ecological indicators, the current shares of ST power systems are only about 50\% (Figure 1).

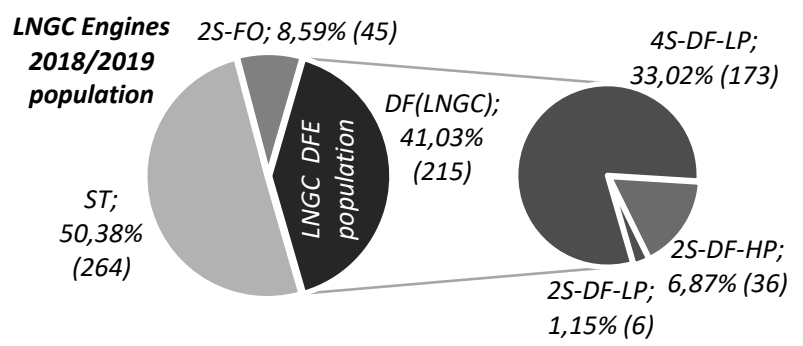

Fig. 1. Quantitative shares of engines of the LNGC population.

Global population of marine DF heat engines (Figure 2) was created using the LNGC population of dual fuel engines (Figure 1) and the population of Liquified Natural Gas Fueled Ships (LNGFS) identified on the basis of [5].

The research problem studied in this work was separated from the identified set of problems on DF heat engines population based on the criterion of its position in the hierarchy of current problems and the number of objects it concerns. The group, constituting $71 \%$ of the global population of marine DF heat engines, are four stroke DF IC engines which uses liquid fuel (Common rail pilot-fuel injection [2]) to ignite natural gas-air lean mixture $(\lambda>1)$. One of the most important problems 
related to this group of engines is the significant emission of methane to the atmosphere $[6,7]$.

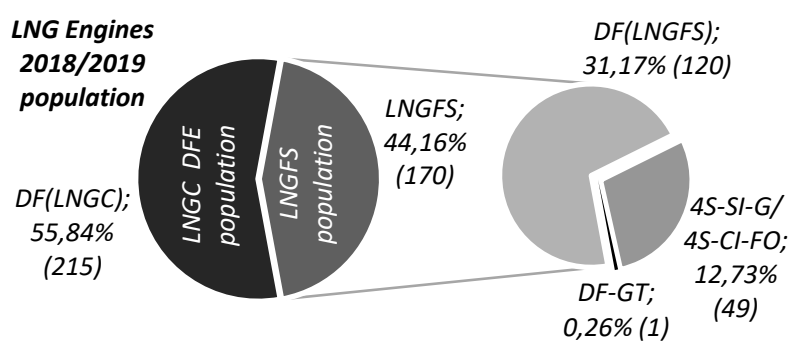

Fig. 2. Quantitative shares of engines of the $\mathrm{LNG}$ population.

Research that has been conducted and described in [6] points out the negative effect of methane slip resulting in excessive greenhouse gases emission. On the other hand, L N G properties potentially limit the described difficulties of waste heat conversion of liquid fuel exhaust gases [3, $8,9,10]$.

The reason to consider the possibility of reducing the methane slip effect by increasing the rate of recovered waste heat of dual-fuel engine exhaust were the following observations:

- possibility of significant reduction of the minimum exhaust gas temperature due to the insignificant sulphur content in LNG $[9,10]$,

- higher temperatures of natural gas exhaust in the turbocharger outlet section than liquid fuel exhaust temperatures [2],

- the possibility of utilizing waste heat at low temperatures in cycles with an organic working medium $[3,8,9,10]$,

- evolution of Organic Rankine Cycle (ORC) marine WHRS, which is proved by the physical implementation of such a system described in [11].

A slightly different position regarding observation a) is presented in publications [12, 13] warning about the observed sulphur content in natural gas that may lead to condensation of sulphuric acid on the heat transfer surface. In the case of the considered group of engines, the sulphur present in the combustion process is also fed in pilot fuel in the amount resulting from the IMO regulation. That is why this study considers the influence of sulphur content in LNG and pilot fuel on:

a) the sulphuric acid condensation temperature,

b) amount of available exhaust waste heat (quantity),

c) exergy of combustion products (quality),

d) the potential to compensate the methane slip effect.

\section{Thermodynamic analysis}

As the subject of this study the combustion products of marine dual fuel four stroke internal combustion engine (MAN B\&W 51/60DF [2]) were considered. Thermodynamic analysis was carried assuming:

- excess air coefficient $\lambda=i d e m=2,2$,

- homogeneous mixture of NG, air and liquid fuel,

- engine maximum effective power $\dot{W}_{e(M)}=1 M W$,

- air parameters - temperature $T_{0}=298,15 \mathrm{~K}$, pressure $p_{0}=101,325 \mathrm{kPa}$ and relative humidity $\varphi=0,7$,
- range of sulphur mass fraction in liquid fuel $0,001 \leq x_{S(F O)} \leq 0,005$ according to IMO [1],

- range of sulphur mole fraction in natural gas $1 \cdot 10^{-6} \leq y_{S(N G)} \leq 20 \cdot 10^{-6}$ according to $[12,13]$.

The molar flow rates balance of NG, FO and air constituents was considered as for an open steady-state thermodynamic system (Figure 3). Combustion products parameters based on abovementioned balance were used to calculate: the condensation temperature of sulphuric acid, exhaust specific heat as a function of temperature later used to establish the time rate of waste heat transfer. The quality of the waste heat source was assessed using exergy and the waste energy quality index. Based on the calculated time rate of exhaust exergy flow the maximum reduction potential of carbon dioxide emission due to ideal energy conversion in WHRS was determined. The methane slip effect was included in the carbon dioxide balance by the methane specific emission and its global warming potential (GWP) indicator.

\subsection{Molar flow rates balance of DF IC engine}

The balance (1) of incoming and outgoing fluids crossing the thermodynamic system boundary (Figure 3 ) is based on matter conservation principle. The molar flow rates entering the control volume are natural gas $\dot{n}_{N G}[\mathrm{~mol} / \mathrm{s}]$, liquid fuel $\dot{n}_{F O}[\mathrm{~mol} / \mathrm{s}]$ and air $\dot{n}_{a}[\mathrm{~mol} / \mathrm{s}]$.

$$
\begin{aligned}
\sum_{i=1}^{m} \dot{n}_{i}+\sum_{j=1}^{n} \dot{n}_{j}+\dot{n}_{a} & =\sum_{k=1}^{n} \dot{n}_{k} \\
\dot{n}_{N G}+\dot{n}_{F O}+\dot{n}_{a} & =\dot{n}_{e x}
\end{aligned}
$$

The outgoing exhaust molar flow rate $\dot{n}_{e x}[\mathrm{~mol} / \mathrm{s}]$ was determined as the sum of incoming molar flow rates.

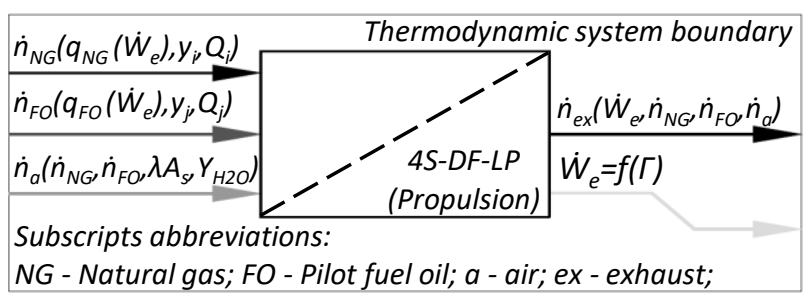

Fig. 3. Diagram of parameters relations in studied system.

Molar flow rates of both fuels $\dot{n}_{F O}+\dot{n}_{N G}[\mathrm{~mol} / \mathrm{s}]$ were determined basing on: the required specific heats of natural gas $\dot{q}_{N G}[J / W s]$ and liquid fuel $\dot{q}_{F O}[J / W s]$ published in [17], components mole fractions $y_{i} \cdot y_{j}$ of fuels and their heat of combustion $\tilde{Q}_{i}, \tilde{Q}_{j}[\mathrm{~J} / \mathrm{mol}]$ taken from $[4,12,13]$.

$\dot{n}_{C_{\alpha} H_{\beta} O_{\gamma} S_{\delta}}=\dot{n}_{F O}+\dot{n}_{N G}=\dot{W}_{e}\left(\frac{\dot{q}_{N G}}{\sum_{i=1}^{m} y_{i} \widetilde{Q}_{i}}+\frac{\dot{q}_{F O}}{\sum_{j=1}^{n} y_{j} \widetilde{Q}_{j}}\right)$

The determined molar flow rates of fuels were used to calculate by equation (4) their mole fractions as a function of engine load $y_{N G}, y_{F O}=f\left(\Gamma=\dot{W}_{e} / \dot{W}_{e(M)}\right)$.

$$
y_{N G}=\frac{\dot{n}_{N G}}{\dot{n}_{C_{\alpha} H_{\beta} O_{\gamma} s_{\delta}}}, y_{F O}=\frac{\dot{n}_{F O}}{\dot{n}_{C_{\alpha} H_{\beta} O_{\gamma} S_{\delta}}}
$$


Due to a significant number of $\mathrm{NG}$ and $\mathrm{FO}$ constituents the analysis of the combustion process was based on the stoichiometric combustion balance of quasimolecule $C_{\alpha} H_{\beta} O_{\gamma} S_{\delta}$ of fuel given by (5).

$$
\begin{gathered}
\dot{n}_{C_{\alpha} H_{\beta} O_{\gamma} S_{\delta}}\left[1+\lambda \tilde{A}_{s}\left(1+3,76+Y_{H_{2} O}\right)\right]= \\
\dot{n}_{C_{\alpha} H_{\beta} O_{\gamma} S_{\delta}}\left\{\alpha+\delta+\frac{\beta}{2}+\lambda \tilde{A}_{s}\left[Y_{H_{2} O}+\left(1-\frac{1}{\lambda}\right)+3,76\right]\right.
\end{gathered}
$$

The stoichiometric mole ratio of oxygen and fuel $\tilde{A}_{s}\left[\operatorname{mol}\left(\mathrm{O}_{2}\right) / 1 \mathrm{~mol}\right]$ was determined basing on eq. (6) and the number of carbon $\alpha$, hydrogen $\beta$, oxygen $\gamma$ and sulphur $\delta$ atoms identified by the system of equations (7).

$$
\begin{gathered}
\tilde{A}_{s}=\alpha+\frac{\beta}{4}-\frac{\gamma}{2}+\delta \\
\left\{\begin{array}{l}
\alpha=y_{N G} \sum_{i=1}^{m} y_{i} \alpha_{i}+y_{F O} \sum_{j=1}^{n} y_{j} \alpha_{j} \\
\beta=y_{N G} \sum_{i=1}^{m} y_{i} \beta_{i}+y_{F O} \sum_{j=1}^{n} y_{j} \beta_{j} \\
\gamma=y_{N G} \sum_{i=1}^{m} y_{i} \gamma_{i}+y_{F O} \sum_{j=1}^{n} y_{j} \gamma_{j} \\
\delta=y_{N G} \sum_{i=1}^{m} y_{i} \delta_{i}+y_{F O} \sum_{j=1}^{n} y_{j} \delta_{j}
\end{array}\right.
\end{gathered}
$$

The mole ratio of water vapor contained in the air to oxygen $\mathrm{Y}_{\mathrm{H}_{2} \mathrm{O}}\left[\mathrm{mol}\left(\mathrm{H}_{2} \mathrm{O}\right) / \operatorname{mol}\left(\mathrm{O}_{2}\right)\right]$ was calculated using equation (8).

$$
Y_{\mathrm{H}_{2} \mathrm{O}}=\frac{n_{\mathrm{H}_{2} \mathrm{O}}}{n_{\mathrm{O}_{2}}} \equiv \frac{p_{\mathrm{H}_{2} \mathrm{O}}}{p_{\mathrm{O}_{2}}}=\frac{\varphi p_{\mathrm{H}_{2} \mathrm{O}(s)}}{y_{\mathrm{O}_{2}}\left(p_{a}-\varphi p_{\mathrm{H}_{2} \mathrm{O}(s)}\right)}
$$

The saturation vapor pressure as a function of temperature $p_{H_{2} O(s)}=f(T)$ was determined using the Antoine equation with the values of coefficients according to [14].

$$
p_{H_{2} O(s)}=e^{\left(A-\frac{B}{T+C}\right)}=e^{\left(16,262-\frac{3799,89}{T-46,38}\right)}
$$

Partial pressures of combustion products components $p_{k}[\mathrm{~Pa}]$ were calculated using Dalton's law given by eq. (10) and molar flow rates balance (1) and (2) solved on the basis of presented equations (3)-(9).

$$
p_{k}=y_{k} p_{e x}=\frac{\dot{n}_{k}}{\sum_{k=1}^{n} \dot{n}_{k}} p_{e x}=\frac{\dot{n}_{k}}{\dot{n}_{e x}} p_{e x}
$$

\subsection{Condensation temperature of $\mathrm{H}_{2} \mathrm{SO}_{4}$}

The sulphuric acid condensation temperature was determined using the Verhoff-Banchero empirical relationship published in [15] as a following function $T_{\mathrm{H}_{2} \mathrm{SO}_{4}(c)}=f\left(p_{\mathrm{H}_{2} \mathrm{O}}, p_{\mathrm{H}_{2} \mathrm{SO}_{4}}\right)$. Partial pressure of water vapor at equilibrium state $p_{\mathrm{H}_{2} \mathrm{O}}\left(p_{\mathrm{H}_{2} \mathrm{O}(a)} ; p_{\mathrm{H}_{2} \mathrm{O}(\beta)}\right)$ was determined using eq. (1)-(10). It was assumed that water vapor is composed of $\mathrm{H}_{2} \mathrm{O}$ molecules introduced with ambient air and $\mathrm{H}_{2} \mathrm{O}$ molecules formed in the hydrogen oxidation process. Partial pressure of sulfuric acid $p_{\mathrm{H}_{2} \mathrm{SO}_{4}}$ is determined by the efficiency of the oxidation process of sulphur dioxide to sulphur trioxide (assumed $\eta_{\mathrm{SO}_{3}}=0,05$ [16]) and the efficiency of the gaseous $\mathrm{SO}_{3}$ and $\mathrm{H}_{2} \mathrm{O}$ conversion process to gaseous $\mathrm{H}_{2} \mathrm{SO}_{4}$ (assumed $\eta_{\mathrm{H}_{2} \mathrm{SO}_{4}}=$ 1 [14]). The determined $\mathrm{H}_{2} \mathrm{SO}_{4}$ condensation temperature was assumed as the minimum temperature of exhaust gases $\left(T_{\mathrm{H}_{2} \mathrm{SO}_{4}(\mathrm{c})}=T_{\mathrm{ex}(1)}\right)$ leaving the WHRS.

\subsection{The rate of exhaust waste heat and exergy}

The rate of exhaust sensible waste heat $\dot{Q}_{e x}$ was identified on the basis of solved balance (11), exhaust gas temperature leaving the turbocharger $T_{\text {ex(0) }}$ [2] and calculated condensation temperature of sulphuric acid assuming that $T_{\mathrm{H}_{2} \mathrm{SO}_{4}(\mathrm{c})}=T_{\mathrm{ex}(1)}$.

$$
\dot{Q}_{e x}=\dot{n}_{e x} \Delta \tilde{h}_{e x}=\dot{n}_{e x} \int_{T_{e x(0)}}^{T_{H_{2} S O_{4}}(c)} \tilde{c}_{p}(T) d T
$$

Molar specific heat was calculated using eq. (12) as the sum of products - mole fractions of exhaust components $y_{k}$ and their molar specific heats as a function of temperature $\tilde{c}_{p k}=f(T)[14,17]$.

$$
\tilde{c}_{p}(T)=\sum_{k=1}^{5} y_{k} \tilde{c}_{p k}(T)=a T^{3}+b T^{2}+c T+d
$$

Equation (13) was obtained substituting the polynomial (12) into the relation (11) and solving the integral within the limits of the identified exhaust temperatures.

$$
\begin{gathered}
\dot{Q}_{e x}=\dot{n}_{e x} \Delta \tilde{h}_{e x}=\dot{n}_{e x} \int_{T_{e x(0)} T_{H_{2} S O_{4}}(c)} \tilde{c}_{p}(T) d T \\
\dot{n}_{e x}\left(\frac{a}{4} \Delta T^{4}+\frac{b}{3} \Delta T^{3}+\frac{c}{2} \Delta T^{2}+d \Delta T\right)
\end{gathered}
$$

Exergy of combustion products indicates the maximum theoretical work that can be obtained in the clock-wise reversible thermodynamic cycle realizing ideal energy conversion, i.e. $B_{e x} \equiv W_{\text {ex (id) }}[J]$. From this it results that the time rate of exhaust exergy flow determines the maximum power that potentially can be generated in the clockwise reversible thermodynamic cycle (maximum time rate of work that can be produced in ideal conditions using exhaust gases as a heat source of reversible cycle), i.e. $\dot{B}_{e x} \equiv \dot{W}_{e x(i d)}[J / s=W]$.

$$
\dot{B}_{e x}=\dot{Q}_{e x} \psi_{e x}=\dot{n}_{e x} \Delta \tilde{h}_{e x}\left(\tilde{b}_{e x} / \Delta \tilde{h}_{e x}\right)=\dot{n}_{e x} \tilde{b}_{e x}
$$

The rate of exhaust gases exergy flow $\dot{B}_{e x}$ was calculated using function of logarithmic mean temperature $\bar{T}_{e x}$ (assumed as only variable parameter) represented by the eq. (15) - waste heat quality index $\psi_{\text {ex }}$ [8]. Sea water was introduced to the thermodynamic cycle as cooling medium of condenser. Assumed fixed cold sink temperature was $T_{0}=298,15 \mathrm{~K}=$ idem.

$$
\psi_{e x}=1-\frac{T_{0}}{\bar{T}_{e x}}=1-\frac{T_{0}}{\left.\frac{T_{\mathrm{ex}(0)^{-T} \mathrm{H}_{2} \mathrm{SO}_{4}(c)}}{\ln \left(T_{\mathrm{ex}(0)} / T_{H_{2}} \mathrm{SO}_{4}(c)\right.}\right)}
$$

Considered waste heat quality index $\psi_{e x}$ in this paper takes into account only the quality of thermal energy, neglecting the energy of exhaust pressure.

\subsection{Emission balance of $\mathrm{CO}_{2}$ considering $\mathrm{CH}_{4}$}

The total mass flow rate of emitted carbon dioxide $\dot{m}_{\Sigma \mathrm{CO}_{2}}[\mathrm{~g} / \mathrm{s}]$ is composed of $\mathrm{CO}_{2}$ molecules formed in combustion process of fuel $\dot{m}_{\mathrm{CO}_{2}}$ and the so-called equivalent $\mathrm{CO}_{2}$ mass flow rate $\dot{m}_{\mathrm{CO}_{2}(e q)}^{\mathrm{CH}_{4}}$. The equivalent mass flow rate of carbon dioxide takes into account the impact of methane on the greenhouse effect through the 
Global Warming Potential (GWP). GWP indicates the amount of heat absorbed of certain mass of $\mathrm{CH}_{4}$ relative to the same mass of $\mathrm{CO}_{2}$. Assuming that the life cycle of $\mathrm{CH}_{4}$ molecule in the atmosphere is hundred years, the GWP of methane is $G W P_{C H_{4}}^{100}=21$ [6].

$$
\dot{m}_{\Sigma C O_{2}}=\dot{m}_{\mathrm{CO}_{2}}+\dot{m}_{\mathrm{CO}_{2}(e q)}^{\mathrm{CH}_{4}}=\dot{W}_{e}\left(\bar{e}_{\mathrm{CO}_{2}}+\bar{e}_{\mathrm{CH}_{4}} G W P\right)(16)
$$

The average specific emission of carbon dioxide $\bar{e}_{\mathrm{CO}_{2}}=444,2 \mathrm{~g} / \mathrm{kWh}$ and methane $\bar{e}_{\mathrm{CH}_{4}}=6,9 \mathrm{~g} / \mathrm{kWh}$ was taken for the considered engine type according to [7].

The maximum reduction of carbon dioxide emission $\Delta \dot{m}_{\mathrm{CO}_{2}(i d)}$ that can be obtained in the ideal process of waste heat conversion of exhaust gases was determined basing on the eq. (14) - the definition of exergy flow rate $\left(\dot{B}_{e x} \equiv \dot{W}_{\text {ex }(i d)}[W]\right)$.

$$
\Delta \dot{m}_{\mathrm{CO}_{2}(\mathrm{id})}=\dot{W}_{\text {ex(id) }}\left(\bar{e}_{\mathrm{CO}_{2}}+\bar{e}_{\mathrm{CH}_{4}} G W P\right)
$$

The potential of the methane slip effect reduction due to ideal conversion of exhaust sensible waste heat into mechanical work was assessed basing on the eq. (18)

$$
\Delta \dot{m}_{\mathrm{CO}_{2}\left(\mathrm{CH}_{4}\right)}=\dot{m}_{\mathrm{CO}_{2}(\mathrm{eq})}^{\mathrm{CH}_{4}}-\Delta \dot{m}_{\mathrm{CO}_{2}(\mathrm{id})}
$$

Fulfilling the inequality $\Delta \dot{m}_{\mathrm{CO}_{2}\left(\mathrm{CH}_{4}\right)}>0$ means that there is no compensation for the methane slip effect, if the inequality $\Delta \dot{m}_{\mathrm{CO}_{2}\left(\mathrm{CH}_{4}\right)}<0$ is fulfilled, the effect is fully compensated.

\section{Analysis results and discussion}

The solution to the problems formulated in the introduction was carried out for two sets of operational parameters of a selected engine determined by the set of engine loads $\Gamma=$ idem $=\{0,5 ; 0,85\}$. The lowest load value $\Gamma=0,5$ was chosen based on the highest sulphur mole fraction criterion (Figure 4), the design load value $\Gamma=0,85$ was chosen based on the highest frequency of occurrence in operational profile. The diagrams in Figures 4 and 5 were calculated for two different values of sulphur mass fraction in $\mathrm{FO}$.

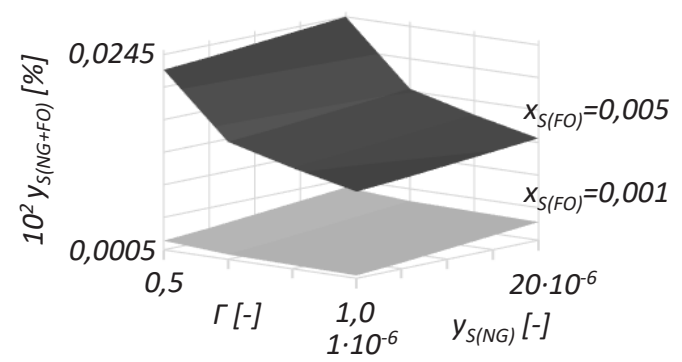

Fig. 4. Total sulphur mole fraction in fuel as a function of engine load and sulphur mole fraction in NG.

In order to solve selected set of problems the following were created, for: problem a) fig. 6 , problem b) fig. 7, 8, 9, problem c) fig. 10, 11, 12, problem d) fig. 13.
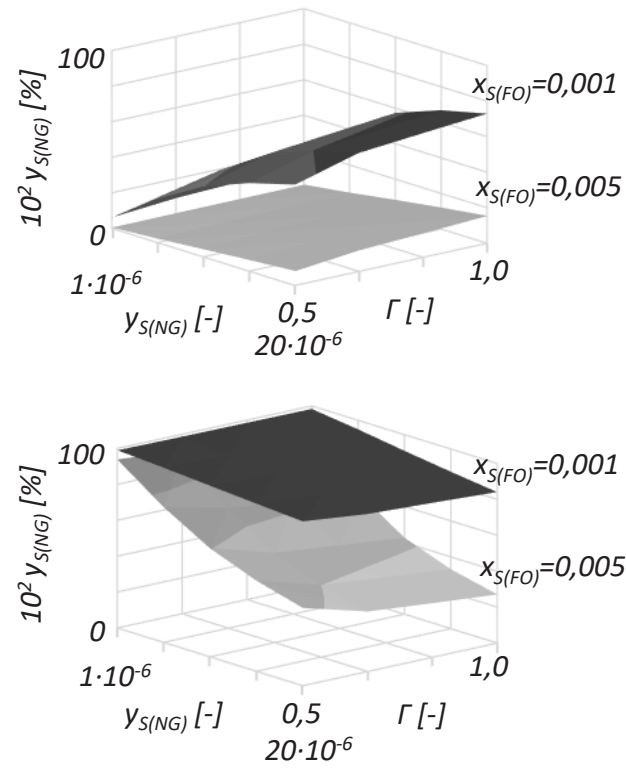

Fig. 5. Sulphur mole fraction of NG and FO as a function of engine load and sulphur mole fraction in NG.

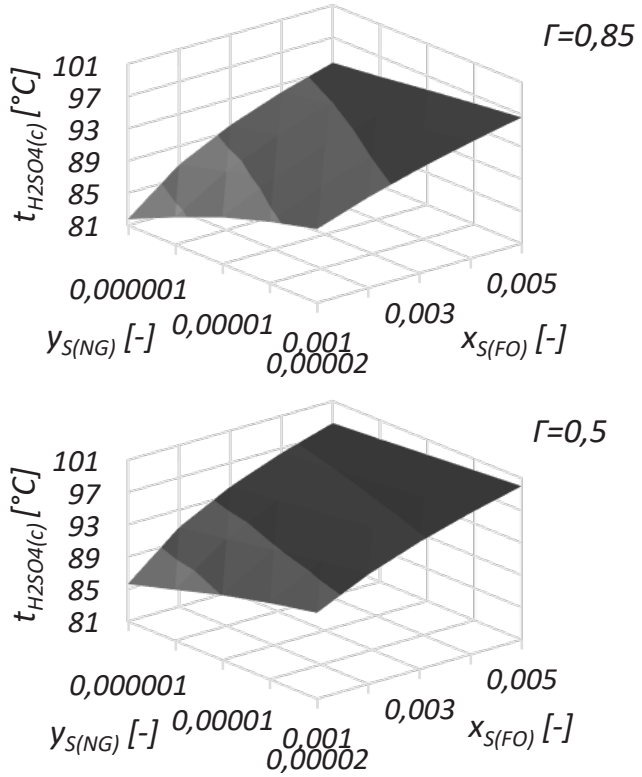

Fig. 6. Condensation temperature of sulphuric acid as a function of sulphur mole fraction in NG and sulphur mass fraction in FO.

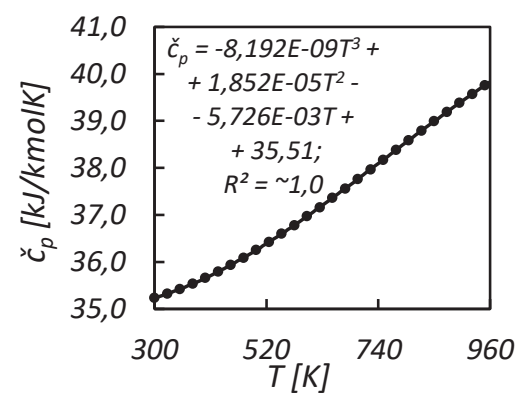

Fig. 7. Molar specific heat of isobaric process of exhaust gases as a function of absolute temperature.

By substituting the coefficients presented in Figure 7 into eq. (13), the relationship (19) describing the rate of 
waste heat flux of exhaust gases $\dot{Q}_{e x}$ as a function of temperature difference was determined.

$$
\begin{gathered}
\dot{Q}_{e x}=\dot{n}_{\text {ex }} \int_{T_{\text {ex }(0)}^{T} \mathrm{H}_{2} \mathrm{SO}_{4}(c)} \tilde{c}_{p}(T) d T=\dot{n}_{\text {ex }} \underbrace{(\underbrace{a / 4} \Delta T^{4}}_{6,173 \cdot 10^{-6}} \Delta T^{4}+ \\
\underbrace{b / 3}_{-2,863 \cdot 10^{-3}} \Delta T^{3}+\underbrace{d / 2}_{35,51} \Delta T)
\end{gathered}
$$

The rates of waste heat of combustion products presented in Figure 9 were calculated using eq. (19) and the temperature differences presented in Figure 8.

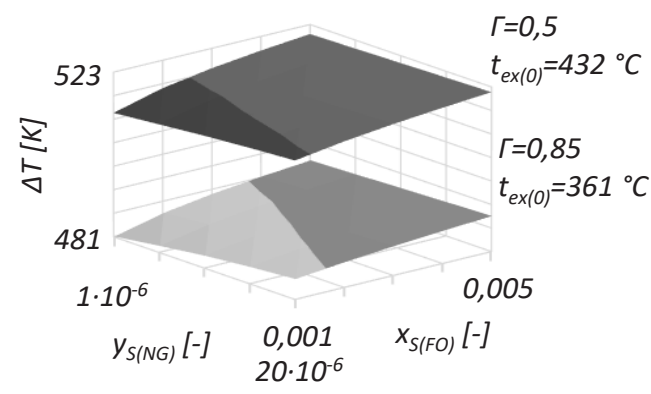

Fig. 8. Temperature differences of combustion products as a function of sulphur fractions - mole in NG and mass in FO.

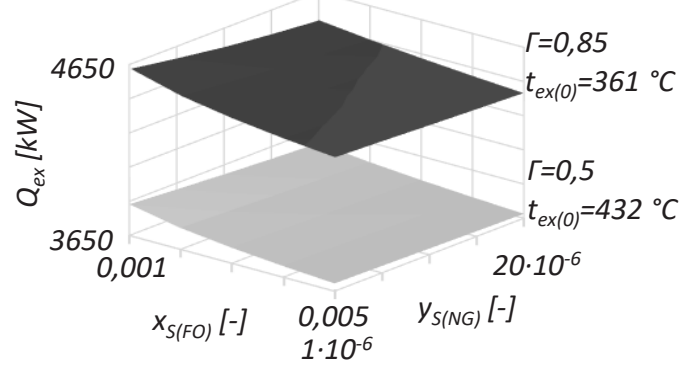

Fig. 9. The rate of combustion products waste heat as a function of sulphur mole fraction in NG and sulphur mass fraction in FO.

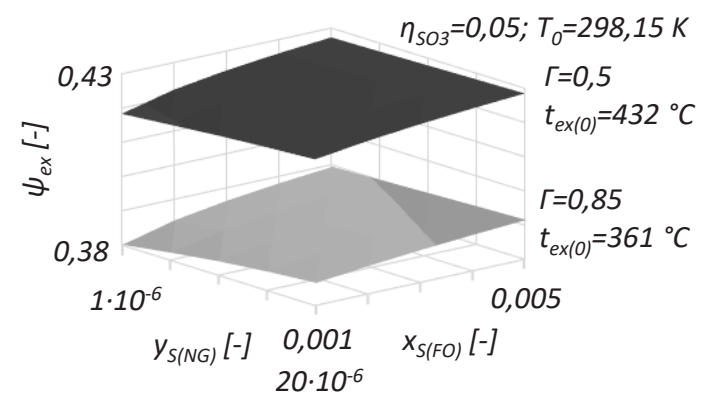

Fig. 10. Waste heat quality index of combustion products as a function of sulphur fractions - mole in NG and mass in FO.

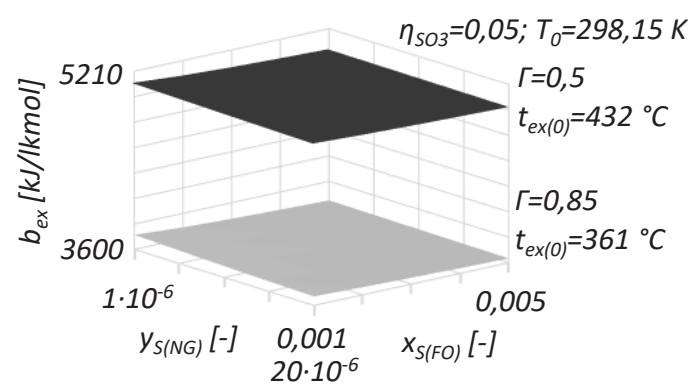

Fig. 11. Molar specific exergy of exhaust gases as a function of sulphur mole fraction in NG and sulphur mass fraction in FO.

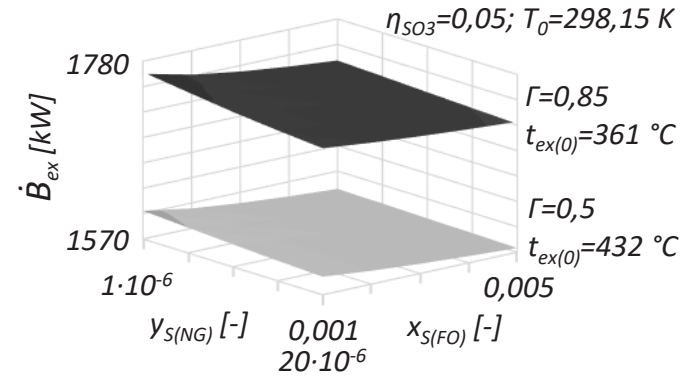

Fig. 12. Exergy flow rate of exhaust gases as a function of sulphur mole fraction in NG and sulphur mass fraction in FO.
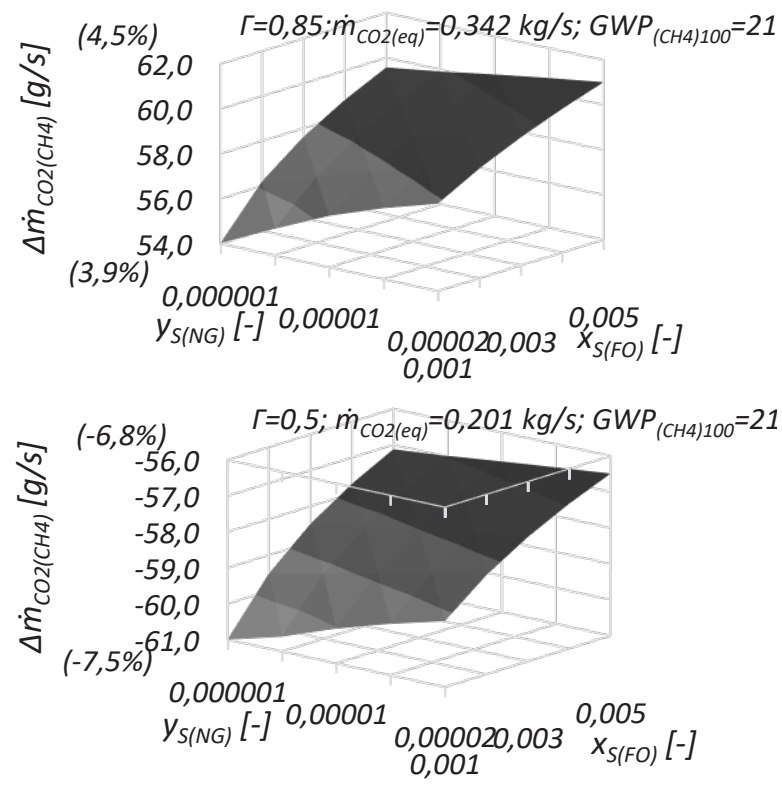

Fig. 13. Equivalent carbon dioxide mass flow rate as a function of sulphur mole fraction in NG and sulphur mass fraction in FO.

According to thermodynamic analysis results the following was observed (notation the same as for identified set of problems):

a) sulphuric acid condensation temperature is influenced by engine load and sulphur content in fuels (Fig. 6). The highest sulphuric acid condensation temperature occurred at engine load of $\Gamma=0,5$ which corresponded with the highest sulphur mole fraction in fuels (Fig. 4).

b) The highest rate of waste heat of combustion products (Fig. 8) was observed at the load of $\Gamma=0,85$ which results from higher molar flow rate, despite lower exhaust temperature differences (Fig. 8). These observations have a significant impact on the quality of waste heat of exhaust.

c) M ore favorable indicators of the waste heat quality of combustion products were observed for the lower engine load of $\Gamma=0,5$ (Fig. 10). The reason for this is the following temperature relation $T_{\text {ex(0) }}(\Gamma=$ $0,5)>T_{\text {ex }(0)}(\Gamma=0,85)$ (with the assumption of constant temperature of the environment). An analogous relationship occurs for molar specific exergies presented in Figure 11. Despite observed differences of analyzed engine loads parameters, the exergy flow rates are comparable (Fig. 12). 
d) The potential to compensate the methane slip effect was observed in Fig. 13 only for the engine load of $\Gamma=0,5$ which satisfied the inequality $\Delta \dot{m}_{\mathrm{CO}_{2}\left(\mathrm{CH}_{4}\right)}>$ 0 . For the engine load of $\Gamma=0,85$ observed equivalent mass flow rate of carbon dioxide satisfied the inequality $\Delta \dot{m}_{\mathrm{CO}_{2}\left(\mathrm{CH}_{4}\right)}<0$ meaning that the methane slip effect was not compensated.

\section{Conclusions and future research}

The present study has examined the influence of future IM $O$ global, and actual (ECA), regulation of sulphur mass fraction in marine fuels, as well as possible volume fraction of sulphur in NG, on the sulphuric acid condensation temperature of four stroke DF IC engine combustion products, thus on the rate of its waste heat and exergy. The particular attention has been paid to the possibility of methane emission compensation by conversion of waste heat in WHRS into effective power. A bove has been assessed only for combustion products using exergy to determine effective power generation limits. Thermodynamic analysis has been conducted for two engine loads - nominal (or design) load $(\Gamma=0,85)$ and low load $(\Gamma=0,8)$. Using values determined in analysis and reported in the literature - the mean specific emission of $\mathrm{CO}_{2}$ and $\mathrm{CH}_{4}$ of four stroke DF IC engine and the Global W arming Potential factor of $\mathrm{CH}_{4}$, the emission rates of $\mathrm{CO}_{2}$, equivalent $\mathrm{CO}_{2}$ (eq. 16) and maximum possible reduction of $\mathrm{CO}_{2}$ emission in the ideal exhaust waste heat conversion process (eq. 17) were determined. $\mathrm{N}$ egative values of balanced $\mathrm{CO}_{2}$ emission rates which are indicating the potential to compensate the methane slip effect were observed only for low engine load.

The results of this study allowed following conclusions to be made:

1. Despite relatively low sulphur volume fractions in NG and mass fraction in pilot $\mathrm{FO}$ the condensation of sulphuric acid can occur at high exhaust temperatures which are also related with engine load. It indicates the importance of $\mathrm{H}_{2} \mathrm{SO}_{4}$ condensation analysis in design process of DF IC engine exhaust sensible waste heat recovery systems on ships in order to utilize maximum energy avoiding at the same time low temperature corrosion of heat transfer surfaces.

2. The main limitation of conducted analysis is the idealization of waste energy conversion process whose assumptions cannot be met in real conditions. However, determined boundary values under these assumptions led to another conclusion.

3. Compensation of four stroke DF IC marine engine methane emission and its influence on global warming by means of exhaust sensible waste heat conversion needs to be supported in real conditions by other $\mathrm{CO}_{2}$ reduction technologies.

The combination of above conclusions and availability of acid-proof engineering materials presented for example in [18] led to the decision on future research in the field of combustion products latent waste heat recovery by introducing condensing heat exchangers to marine power plants.

\section{References}

1. Lloyd's Register, Future IMO and ILO Legislation, (2019).

2. MAN B\&W, MAN 51/60DF Project Guide, (2017).

3. Wu Sh.-Y., Li Ch., Xiao L., Li Y.-R., Liu Ch., The role of outlet temperature of flue gas in organic Rankine cycle considering low temperature corrosion, Journal of Mechanical Science and Technology, Vol. 12, pp. 5213-5219, (2014).

4. International Gas Union, World LNG Report, (2019).

5. DNV-GL, LNG fueled fleet statistics, (2019), available at: http.://afi.dnvgl.com/Statistics, (accessed 22.09.2019).

6. Attah E. E., Bucknall R., An analysis of the energy efficiency of LNG ships powering options using the EEDI, Ocean Engineering, Vol. 110, pp. 62-74, (2015).

7. Stenersen D., Thonstad O., GHG and NOx emissions from gas fueled engines, SINTEF Ocean AS, (2017).

8. Adamkiewicz A., Michalski R., Zeńczak W., Wybrane problemy technologii konwersji energii w okrętowych systemach energetycznych, Kaprint, (2012).

9. Mondejar M. E., Andreasen J. G., Pierobon L., Larsen U., Thern M., Haglind F., A review of the use of organic Rankine cycle power systems for maritime applications, Renewable and Sustainable Energy Reviews, Vol. 91, pp. 126-15, (2018).

10. Singh D. V., Pedersen E., A review of waste heat recovery technologies for maritime applications. Energy Conversion and Managment, Vol. 111, pp. 315-328, (2016).

11. Haglind F., Mondejar M. E., Andreasen J. G., Pierobon L., Meroni A., Organic Rankine cycle unit for waste heat recovery on ships (Pilot ORC), Danish Technical University, (2017).

12. CIMAC, Impact of Gas Quality on Gas Engine Performance, (2015).

13. The European Association of Internal Combustion Engine Manufacturers, Total Sulphur Levels in Natural Gas with Special Consideration of IC Engines, (2012).

14. Szarawara J., Termodynamika chemiczna, Wydawnictwa Naukowo-Techniczne, (1985).

15. Verhoff F. H., Banchero J. T., Predicting dew points of flue gases, Chemical Engineering Progress, Vol. 8, pp. 71-72, (1974).

16. Cordtz R., Schramm J., Rabe R.: Investigating $\mathrm{SO}_{3}$ formation from the Combustion of Heavy Fuel Oil in a Four-Stroke Medium-Speed Test Engine, Energy \& Fuels, Vol. 10, pp. 6279-6286, (2013).

17. Burcat A., Ruscic B., Third Millennium Ideal Gas and Condensed Phase Thermochemical Database for Combustion with updates from Active Thermochemical Tables, Argonne National Laboratory, (2005).

18. Xiong Y., Tan H., Wang Y., W., Mikulčić H., Duić N., Pilot-scale study on water and latent heat recovery from flue gas using fluorine plastic heat exchangers. Journal of Cleaner Production, Vol. 161, pp. 1416-1422, (2017). 